\title{
Membentuk Karakter Kreatif : Bergerak Melalui Stimulus Permainan Tradisional
}

\author{
Agus Budiman \\ Departemen Pendidikan Seni Tari FPSD-UPI \\ agusbudiman@upi.edu \\ Dewi Karyati \\ Departemen Pendidikan Seni Tari FPSD-UPI \\ dekar@upi.edu
}

\begin{abstract}
This study aimed to obtain result overview of dance learning in dance extracurricular activities as application of creative character education in elementary school. The method used in this research was an experimental method with data collection techniques through observation studies, techniques, literature studies, interview techniques and documentation studies. The sample consisted of 23 elementary school students at SD Lab UPI School. The findings show that the process of strengthening character education in dance extracurricular activities can be realized through various character learning habits that can be done at several stages of learning activities. The conclusion of this study is the strengthening of character education in students can be achieved in extracurricular dance activities through prayer learning activities, singing national songs, independent and group learning, creative processes, appreciation and creation.
\end{abstract}

Keyword: Creative, Stimulation, Strengthening Character Education, Dance Extracurricular

\section{Pendahuluan}

Mengajar seni tari di sekolah tidak hanya mengajar tentang gerak saja kepada anak. Pendidikan tari memberikan kesempatan kepada siswa mengembangkan dan mendemonstrasikan keterampilan kreatif (Ashley, 2019; Connell, 2009; Marques, 2016; Torrents Martín, Ric, \& Hristovski, 2015). Proses menciptakan, melakukan, dan menghargai yang melekat dalam kreatif aktivitas kegiatan pembelajaran tari (J M Smith-Autard, 2010; Jacqueline M Smith-Autard, 2002). Selain itu, pembelajaran tari untuk mewujudkan artikulasi imajinasi dalam tarian (Kassing \& Jay, 2020; Redfern, 1982; Jacqueline Mary Smith-Autard, 2000). Kreativitas dan bermain dalam pembelajaran tari dapat mengembangan model keterampilan artistik siswa (Chappell, 2007; Chappell \& Hathaway, 2019; Schwartz, 1993). Berbagai aktivitas belajar tersebut sebagai bagian dari proses tari kreatif (Connery, John-Steiner, \& Marjanovic-Shane, 2010; Lindqvist, 2001; Press \& Warburton, 2007).

Ekspresi dalam tari pada dasarnya dapat ditunjukan pada dua bagian yaitu tubuh dan wajah manusia (Kanwisher, McDermott, \& Chun, 1997). Ekspresi tubuh dan wajah ini akan muncul ketika terdapat stimulus yang merangsang imajinasi pikiran manusia yang diaktualisasikan melalui bahasan gerak tubuh dan wajah manusia. Stimulus dapat didefinisikan sebagai sesuatu yang membangkitkan pikiran, atau roh, atau menghasut aktivitas. Stimulus untuk komposisi tari dapat berupa pendengaran, visual, ideasional, taktil atau kinestetik(Davenport, 2006; Jacqueline Mary Smith-Autard, 2000; Warburton, 2005). Secara umum stimulus dalam tari 
mengoptimalkan segala potensi yang ada pada tubuh manusia seperti potensi pendengaran, penglihatan, kepekaan rasa, kepekaan berimajinasi, dan kemampuan mengembangkan daya pikirnya.

Pemikiran tentang konsep tari model banyak dalam pemikiran Rudolf Laban dan Margaret H'Doubler (Brown, 2014). (Maletic, 2011; Von Laban, 1975), menjelaskan '... bukan kesempurnaan artistik atau kreasi atau pertunjukan tarian sensasional yang ditujukan untuk, tetapi efek menguntungkan dari aktivitas kreatif menari pada kepribadian murid. (H'Doubler \& Claxton, 1957) menjelaskan juga bahwa '... pendidikan tari harus emosional, intelektual, dan spiritual, serta fisik, jika tari ingin berkontribusi pada tujuan pendidikan yang lebih besar'. Pemikiran-pemikiran ini yang mesti dijadikan dasar para guru dalam memwujudkan pembelajaran tari di sekolah. Oleh karena kebanyakan guru seni tari di sekolah hanya fokus pada mengajarkan tentang gerak yang terdapat pada sebuah tarian.

Pendidikan tari saat ini harus mempersiapkan model pembelajaran tari yang sesuai dengan semangat budaya belajar tari di abad 21 (Risner, 2010; Sööt \& Viskus, 2013; S. W. Stinson, 2010). Konsep pendidikan tari di sekolah tidak mengarahkan anak untuk menjadi seorang penari (Koff, 2000). Siswa belajar tari di sekolah agar memiliki perubahan dari berbagai dimensi kemampuan, yakni kemampuan kognitif, afeksi dan psikomotor. Dimensi kemampuan ini yang mengarahkan pencapaian hasil belajar seutuhnya bagi siswa. Pendidikan karakter menjadi salah satu dimensi hasil belajar yang proses pembentukannya akan melalui tahapan pencapaian pembelajaran kognitif, apektif dan psikomotor. Pendekatan pedagogi tari secara konvensional model pembelajaran lebih menekankan pada proses transmisi pengajaran yang memiliki tujuana siswa belajar dengan meniru ragam gerakan yang dicontohkan gurunya di depan kelas (Sööt \& Viskus, 2014). Dalam konsep pembelajaran modern anak tidak banyak diarahkan untuk mampu menirukan gerakan yang dicontohkan guru, tapi bagaimana agar siswa mengembangkan kemampuan kreatifnya untuk dapat berkreasi dalam tari (Georgios, 2017).

Dalam kebijakan kurikulum pendidikan nasional fokus penguatan pendidikan karakter meliputi: penguatan pendidikan karakter religius, nasionalis, mandiri, gotong royong, dan integritas. Kegiatan ekstrakurikuler tari di sekolah diharapkan menjadi salah satu wadah kegiatan siswa yang harus diikuti untuk menopang kualitas kegiatan pembelajaran di intrakurikuler khususnya dalam masalah implementasi penguatan pendidikan karakter. Pembinaan akhlak siswa merupakan salah satu tujuan dari pendidikan karakter (Karmini, 2020). Pendidikan karakter di sekolah dapat dimaknai hal positif apa saja yang akan berpengaruh kepada siswa dari hasil pembelajaran yang dilakukan (Rosala \& Budiman, 2020). Begitupun implementasi pendidikan seni tari di sekolah harus mampu membentuk karakter positif pada diri siswa, meskipun pada dasarnya konsep pendidikan seni di sekolah secara praktis dapat dimaknai sebagai upaya membentuk keterampilan siswa agar memiliki keterampilan dalam bidang seni yang dipelajari (Budiman, Nugraheni, \& Purnomo, 2020).

Pengembangan karakter adalah tugas seumur hidup sekaligus sebagai tantangan menyenangkan bagi seseorang untuk belajar (Murphy, Madonna M., 2009). Akan tetapi pendidikan karakter yang baik dapat dimulai sejak seseorang masih anakanak agar kelak menjadi sebuah kebiasaan baik yang dilakukan dalam kehidupan sehari-hari. Pembelajaran tari di sekolah seyogianya mampu mewujudkan pendidikan karakter bagi seseorang agar dapat berprilaku baik dalam kehidupan sehari-harinya. Melalui kegiatan pembelajaran tari siswa diharapkan memiliki akhlak dan prilaku sesuai dengan norma-norma yang berlaku di masyarakat. Karena masalah pendidikan karakter akan berkaitan dengan nilai dan prilaku yang menjadi karakter suatu masyarakat (McElmeel, 2002). Mewujudkan pembelajaran 
tari kreatif salah satunya bertujuan untuk pengembangan kepribadian global individu, mempersiapkan mereka untuk partisipasi sukses mereka dalam kehidupan publik, ekonomi dan budaya (Davis, 1995; Dimondstein, 1974; Georgios, 2018; S. Stinson, 1988).

Tujuan penelitian ini adalah ingin memperoleh gambaran hasil penerapan pembelajaran tari dengan menggunakan stimulus permainan tradisional anak. Penerapan konsep pembelajaran tari ini dilakukan untuk dapat membentuk karakter anak sekolah dasar (Kamilia, Herdhiana, \& Hermawan, 2019). Permainan tradisional anak adalah kearifan lokal yang dimiliki dimasing-masing daerah dengan karaktersitik yang berbeda-beda (Dermawan, Purnama, \& Mahyudin, 2020). Jawa Barat merupakan salah satu provinsi di Indonesia yang beberapa daerah di wilayah Jawa Barat memiliki potensi kearifan lokal permainan tradisional yang sering dimainkan oleh anak-anak baik di pedesaan maupun diperkotaan. Kearifan lokal permainan tradisional ini yang menjadi stimulus materi pembelajaran tari untuk mendidik karakter anak melalui nilai-nilai kearifan lokal dalam permainan tradisional yang dimanifestasikan melalui bahasan gerak kreatif anak sekolah dasar. Salah tujuan implementasi pendidikan karakter adalah mewujudkan individu yang aktif dan kreatif (Setiono, Yuliantini, \& Dadi, 2020) melalui kegiatan ektrakurikuler di sekolah (Luthviyani, Setianingsih, \& Handayani, 2019).

\section{Metode}

Dalam penelitian ini digunakan metode eksperimen dengan pendekatan kuantitatif untuk mengetahui hasil penerapan pembelajaran melalui permaianan tradisional anak dalam mengembangkan karakter siswa sekolah dasar. Kegiatan penelitian ini dilakukan dalam kegiatan ekstrakurikuler tari yang dilaksanakan di SD Lab. School UPI. Proses penerapan pembelajaran tari dilakukan oleh peneliti dan salah satu mahasiswa tari UPI yang menjadi aplikan pada saat penerapan pembelajaran tari diberikan. Kegiatan penelitian dilakukan dalam empat kali pertemuan yang masingmasing pertemuan dilakukan dalam durasi waktu 2x35 menit. Dalam implementasinya kami melibatkan guru setempat utnuk membantu mengkondisikan pembelajaran yang dilakukan dan mengevaluasi setiap pertemuan pembelajaran dilakukan.

Penelitian ini dilakukan di SD Lab. School UPI Bandung yang beralamat di jalan Setiabudhi no. 229 Kota Bandung. Partisipan penelitian ini melibatkan 23 siswa sekolah dasar yang terdiri dari 8 siswa kelas $6(n=8), 6$ orang siswa kelas $5(n=6)$, dan 9 orang siswa kelas 6 SD $(n=6)$. Selain siswa dalam penelitian ini melibatkan juga 1 mahasiswa sebagai aplikan pada pertemuan $1-2$ dan salah satu peneliti yang berperan sebagai aplikan pada pertemuan 3 - 4. Dipilihnya 23 siswa dalam penelitian karena yang memiliki kegiatan ekstrakurikuler tari di SD Lab. School UPI pada kelas tinggi sebanyak 23 siswa.

Instumen penelitian yang digunakan lebih mengotimalkan instrument pengematan hasil belajar siswa dalam mengembangkan kemampuan kreatifnya. (J M SmithAutard, 2010) menjelaskan beberapa tahapan proses kreatif dalam membuat komposisi dalam tari yang diterapkan dalam penelitian ini seperti tahapan, mengeskplor gerakan masing-masing siswa, melakukan proses inspirasi dan imajinasi, merespon stimulus yang dirasakan, orisinalitas dan spontanitas, fleksibilitas dan pemikiran yang berbeda dengan sebelumnya, Interpretasi tema yang dapat diperoleh dari pengalaman hidup siswa untuk dapat dimuculkan dalam gerakan. Indicator proses kreatif yang dijelaskan oleh (J M Smith-Autard, 2010) diadaptasi kembali oleh peneliti sesuai dengan kebutuhan penelitian. Untuk mengukur ketercapaian hasil belajar siswa digunakan skala likers 1 - 4 yang 
dideskripsikan kembali ke dalam beberapa kriteria keberhasilan belajar siswa dalam mewujudkan kreativitas gerak tari.

Tabel 1. Uji Validitas

\begin{tabular}{ccccc}
\hline Item & Nilai R Hitung & Nilai R Tabel & Nilai sig & Keputusan \\
\hline 01 & 0,760 & 0,456 & $5 \%$ & Valid \\
02 & 0,706 & 0,456 & $5 \%$ & Valid \\
03 & 0,790 & 0,456 & $5 \%$ & Valid \\
04 & 0,528 & 0,456 & $5 \%$ & Valid \\
05 & 0,866 & 0,456 & $5 \%$ & Valid \\
06 & 0,612 & 0,456 & $5 \%$ & Valid \\
07 & 0,454 & 0,456 & $5 \%$ & Tidak Valid \\
08 & 0,790 & 0,456 & $5 \%$ & Valid \\
09 & 0,528 & 0,456 & $5 \%$ & Valid \\
10 & 0,866 & 0,456 & $5 \%$ & Valid \\
\hline
\end{tabular}

Berdasarkan data table hasil uji validitas di atas, 9 item angket dinyatakan valid, sedangkan 1 item angket dinyatakan tidak valid. Dalam penelitian ini tidak dilakukan uji validasi ulang jadi hanya menggunakan 9 item istrumen yang digunakan untuk mengambil data hasil penelitian.

Tabel 2. Uji Reabilitas

\begin{tabular}{rr}
\hline Cronbach's Alpha & \multicolumn{1}{c}{ N of Items } \\
\hline .878 & 10 \\
\hline
\end{tabular}

Dari data hasil uji reabilitas di atas diperoleh hasil $\mathrm{r}$ hitung $=0,878$, dan $\mathrm{r}$ table $=$ $0,456, \quad R$ hitung $>\mathrm{R}$ Tabel $=0,878>0,456$. Data ini menunjukan bahwa instrument yang digunakan dinyatakan reliable.

Data penelitian diperoleh dari hasil observasi dan wawancara pada siswa serta aplikan yang menjadi partisipan penelitian. Proses observasi dilakukan pada saat melakukan aktivitas pembelajaran seperti aktif dalam pembelajaran dan menunjukan kreativitasnya dalam mengembangkan ide dan gagasan baru dalam pembelajaran (Studente, Seppala, \& Sadowska, 2016). Proses kreatif siswa diukur dari bentuk aktivitas siswa pada saat mengembangkan gerak-gerak kreatif dari permainan tradisional yang diperagakan masing-masing siswa. Dalam proses pengumpulan data dilakukan juga melalui proses wawancara untuk memperoleh data tambahan dari guru yang menjadi aplikan peneliti pada saat menerapkan pembelajaran tari melalui permaianan tradisional anak.

Analisis data lebih difokuskan pada pengolahan data secara kuantitatif atau angkaangka. Penyajian data penelitian dilakukan melalui table angka, dan grafik hasil analisis data peneltian. Untuk catatan observasi digunakan beberapa teknik yaitu melalui catatan kegiatan tiap pertemuan, dokumentasi berupa foto-foto kegiatan (Brugar \& Roberts, 2017), dan pedoman observasi serta pedoman wawancara yang digunakan observer pada saat pelaksanaan penelitian. Teknik analisis data menggunakan program SPSS window 0.22 .

\section{Hasil}

Proses Penerapan Permainan Tradisional Anak Dalam Pembelajaran Tari Berdasarkan perencanaan di awal bahwa penelitian ini akan melihat implementasi pembelajaran model penguatan pendidikan karakter dalam kegiatan ektrakurikuler tari di SD Labschool UPI Bandung. Kegiatan penelitian dalam menerapkan model penguatan pendidikan karakter dilakukan selama kurang lebih 1 bulan lebih. Dalam pembelajarannya materi yang diberikan pada kegiatan ekstrakurikuler tari adalah 
lagu kaulinan barudak oray-orayan. Pemilihan materi ini lebih difokuskan pada pengembangan materi pembelajaran berbasis kearifan lokal Jawa Barat sehingga diharapkan mampu meningkatkan daya apresiasi siswa khususnya dalam mengenal budaya permainan trandisional Jawa Barat melalui kegiatan ekstrakurikuler tari.

Pada pelaksanaan kegiatan pembelajaran, peneliti membutuhkan 5 pertemuan yang berlangsung selama 4 minggu, dengan alokasi waktu $2 \times 30$ menit di setiap minggunya dan dilangsungkan pada setiap hari rabu. Dalam setiap pertemuannya, peneliti selalu memberikan materi yang dalam proses pembelajarannya selalu menekankan pada proses penguatan pendidikan karakter. Materi tari yang diberikan pada siswa adalah tari oray-orayan atau tari kaulinan barudak urang lembur yang sudah dikembangkan peneliti dalam kegiatan penelitian sebelumnya. Materi tari ini memiliki nilai-nilai kearifan lokal yang relevan dengan proses pembelajaran yang akan dilakukan yakni proses penguatan pendidikan karakter kepada siswa melalui kegiatan ekstrakurikuler tari. Berikut adalah langkahlangkah pembelajaran uang dilakukan peneliti pada setiap pertemuannya.

Tabel 1. Tahapan Pokok Pembelajaran Tari Sebagai Penguatan Pendidikan Karakter Dalam Kegiatan Ekstrkurikuler

\begin{tabular}{|c|c|}
\hline Tahapan Pembelajaran & Deskripsi Kegiatan Belajar \\
\hline \multirow{3}{*}{ Pembuka } & - Melakukan Kegiatan Berdoa \\
\hline & - Menyanyikan Lagu Nasional \\
\hline & - Mengabsen Kehadiran \\
\hline \multirow{6}{*}{ Inti } & $\begin{array}{l}\text { - Apresiasi Tari Kaulinan } \\
\text { - Analisis Tarian }\end{array}$ \\
\hline & - Belajar Lagu Dalam Permaian Tradisional \\
\hline & - Belajar Permaian Tradisional \\
\hline & - Eksplorasi Gerak \\
\hline & $\begin{array}{l}\text { - Belajar Tari kaulinan secara individu dan } \\
\text { kelompok }\end{array}$ \\
\hline & $\begin{array}{l}\text { - Mengkreasi Gerak Permaianan Menjadi } \\
\text { Gerak Tari ecara individu dan kelompok }\end{array}$ \\
\hline \multirow{3}{*}{ Penutup } & - Menyimpulkan kegiatan belajar \\
\hline & $\begin{array}{l}\text { - Menerapkan hasil belajar dalam kehidupan } \\
\text { sehari-hari }\end{array}$ \\
\hline & - Berlatih secara mandiri \& kelompok \\
\hline
\end{tabular}

Kegiatan pembelajaran ini memiliki tujuan yaitu Siswa diharapkan memiliki pembiasaan sikap religius, nasionalis, mandiri, gotong royong dan integritas melalui kegiatan apresiasi tari tradisional anak-anak berbasis kearifan lokal daerah Jawa Barat. Materi yang dikembangkan dalam penelitian ini adalah tari kaulinan barudak (tari permaianan anak-anak). Metode yang digunakan dalam pembelajaran menggunakan metode apresiasi, demonstrasi, latihan, peniruan, kreatif dan metode kerja kelompok. Sumber belajar menggunakan media audio visual, sementara penilaian hasil belajar dilakukan dalam bentuk penilaian praktek secara individu dan kelompok. Secara umum kegiatan pembelajaran tari dalam kegiatan ekstrakurikuler tari dilakukan sebagai berikut:

\section{Berdoa}

Sebelum kegiatan pembelajaran dilakukan seluruh siswa dibelajarkan untuk melakukan kegiatan berdoa yang baik. Kegiatan berdoa ini untuk selalu mengajarkan kepada siswa agar pada saat melakukan berbagai kegiatan harus dibiasakan dengan melakukan berdoa dulu. Tahapan kegiatan ini dilakukan untuk mendidik siswa dalam penguatan karakter religious.

\section{Menyanyikan Lagu Nasional}

Kegiatan menyanyikan lagu nasional adalah salah satu tahapan yang dilakukan pada setiap pertemuan pembelajaran. Kegiatan menyanyikan salah satu lagu wajib 
nasional dilakukan pula dalam beberapa bidang pelajaran di sekolah dasar, Kegiatan ini semeta-mata untuk menumbuhkan rasa cinta kepada tanah air atau menumbuhkan karakter nasionalisme kepada siswa.

\section{Apresiasi Tari Kaulinan}

Kegiatan pembelajaran ini dilakukan di awal kegiatan inti untuk memberikan pemahaman dan pengetahuan kepada siswa tentang bentuk-bentuk permainan tradisional yang dikembangkan menjadi sebuah tarian. Dalam kegiatian pembelajaran ini siswa diarahkan untuk dapat memahami isi dan makna teks syair lagu yang terdapat pada permainan tradisional anak. Selain dapat memahami isi dan makna teks syair lagu permaianan tradisional, siswa diarahkan untuk dapat mempelajari lagu dalam permaianan tradisional sambil memperagakan gerakan yang terdapat pada permainan tradisional yang dipelajarinya.

\section{Eksplorasi Gerak Tari}

Kegiatan eksplorasi dilakukan setelah siswa distimulus melalui kegiatan apresiasi tarian kaulinan barudak (permaianan anak) yang dilakukan sebelum kegiatan eksplorasi dilakukan. Dalam kegiatan eksplorasi siswa diarahkan untuk mengembangkan gerak-gerak kreatif sesuai dengan karakteristik permainan tradisional yang dipelajari. Siswa mengeksplor beberapa gerak kreatif yang disesuaikan dengan iringan musik tarian kaulinan yang dijadikan materi pelajaran.

\section{Kreasi Gerak Tari}

Kegiatan kreasi gerak tari dilakukan oleh siswa setelah mempelajari beberapa gerak dasar dalam materi tari kaulinan. Siswa diarahkan untuk dapat mengkreasi sendiri bentuk-bentuk gerak dasar yang terdapat dalam tari kaulinan menurut kemampuan masing-masing. Kegiatan mengkreasi gerak tari dilakukan secara kelompok belajar agar siswa dapat saling bekerja sama dalam mengembangkan gagasan gerak kreatif sesuai dengan materi gerak dasar dalam tari kaulinan.

\section{Mempresentasikan Hasil Belajar}

Kegiatan mempresentasikan adalah salah satu tahapan pembelajaran untuk menumbuhkan sikap berani dan tanggung jawab kepada diri siswa. Kegiatan tampil ke depan dilakukan secara individu dan kelompok untuk memperagakan gerakangerakan hasil eksplorasinya. Selain itu, kegiatan tampil ke depan untuk melatih kesiapan dan disiplin siswa dalam mempelajari materi tari yang diberikan oleh guru. Pengukuran hasil belajar pada tahapan ini tidak menilai kualitas gerakan yang ditampilkan siswa, tetapi lebih ke proses pembentukan karakter berani, tanggung jawab, kreatif, dan disiplin dalam memahami materi yang diberikan guru untuk diperagakan ulang di depan teman-temannya.

\section{Memaknai Hasil Belajar}

Tahapan kegiatan belajar ini dilakukan di akhir untuk menyimpulkan bersamasama esensi kegiatan belajar yang telah dilakukan oleh siswa. Kesimpulan yang dibuat berdasarkan makna kegiatan pembelajaran yang dilakukan siswa selama beberapa kali pertemuan. Nilai-nilai pendidikan karakter yang terdapat dalam permainan tradisional yang dipelajari diharapkan dapat diterapkan oleh siswa dalam kehidupan sehari-harinya.

\section{Hasil Uji Regresi Linier Sederhana}

Hasil kegiatan pembelajaran tari untuk meningkatkan penguatan pendidikan karakter kreatif siswa dalam kegiatan ekstrakurikuler tari dianalisis menggunakan teknik analisis uji regresi linier sederhana dengan menggunakan SPSS window 0.22. teknik analisis dilakukan dalam menguji variabel $\mathrm{X}$ (pembelajaran tari) terhadap variabel Y (penguatan pendidikan karakter kreatif). Data penelitian diperoleh dari hasil evaluasi proses pembelajaran dengan menggunakan skala nilai 1-5 dengan 
interval skor standar nilai 0-25 (kriteri 1), 26-50 (kriteria nilai 2), 51-75 (kriteria nilai 3), 76-100 (kriterian nilai 4). Analisis regresi linier sederhana digunakan untuk menilai konsistensi penilaian kemampuan kreatif siswa dalam mengikuti proses pembelajaran tari. Adapun secara rinci hasil uji regersi linier sederhana di visualisasikan dalam table output SPSS sebagai berikut.

Model Summary

\begin{tabular}{lcccr}
\hline \multicolumn{5}{c}{ Model Summary } \\
Model & R & R Square & $\begin{array}{c}\text { Adjusted R } \\
\text { Square }\end{array}$ & $\begin{array}{c}\text { Std. Error of } \\
\text { the Estimate }\end{array}$ \\
\hline 1 & $.580^{\mathrm{a}}$ & .336 & .305 & 3.64237 \\
\hline a. Predictors: (Constant), Pembelajaran Tari &
\end{tabular}

Tabel di atas menjelaskan besaran nilai korelasi/hubungan (R) yaitu 0.580. dari output tersebut diperoleh koefisien determinasi (R Square) sebesar 0.336, yang mengandung pengertian bahwa pengaruh variable bebas (pembelajaran tari) terhadap variable terikat (penguatan pendidikan karakter kreatif) adalah 33,6 \%.

\begin{tabular}{llrrrrr}
\multicolumn{7}{c}{ ANOVA $^{\mathbf{a}}$} \\
\hline Model & & Sum of Squares & df & Mean Square & F & Sig. \\
\hline 1 & Regression & 141.223 & 1 & 141.223 & 10.645 & $.004^{\text {b }}$ \\
& Residual & 278.604 & 21 & 13.267 & & \\
& Total & 419.826 & 22 & & & \\
\end{tabular}

a. Dependent Variable: Penguatan Karakter Kreatif

b. Predictors: (Constant), Pembelajaran Tari

Dari output tersebut diketahui bahwa nilai $\mathrm{F}$ hitung $=10.645$ dengan tingkat signifikansi sebesar $0.000<0,04$, maka model regresi dapat dipakai untuk memprediksi variavel penguatan pendidikan karakter kreatif atau dengan kata lain ada pengaruh variabel pembelajaran tari $(\mathrm{X})$ terhadap variabel $(\mathrm{Y})$.

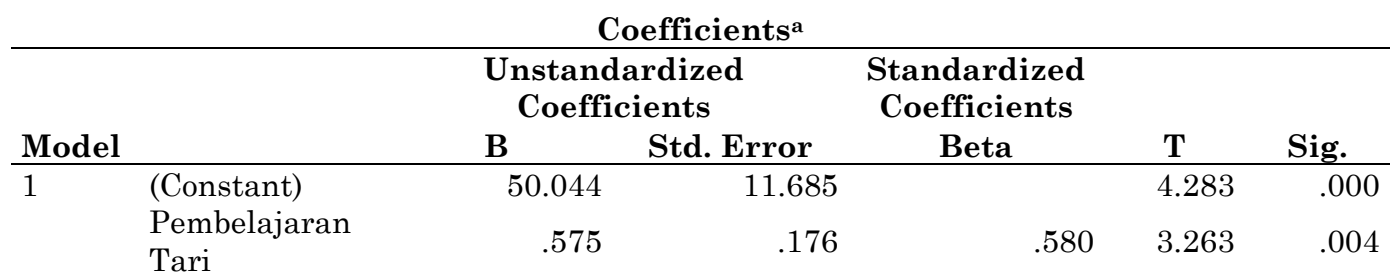

a. Dependent Variable: Penguatan Karakter Kreatif

- Konstan sebesar 50.044, mengandung arti bahwa nilai konsisten variable hasil belajar adalah sebesar 50.044 .

- Koefisien regresi X sebesar 0.575

- $\quad$ menyatakan bahwa setiap penambahan 1\% nilai pembelajaran tari, maka nilai penguatan pendidikan karakter kreatif siswa bertambah sebesar 0.575 . Koefisien regresi tersebut bernilai positif, sehingga dapat dikatakan bahwa arah pengaruh variable $\mathrm{X}$ terhadap $\mathrm{Y}$ adalah posistif.

\section{Pembahasan}

Menilai proses kreatif dalam tari dapat diamati dari poses siswa mengakumulasi pengalaman dalam mengeksplorasi dan menemukan gerakan (Lavender, 2006). Dalam penelitian ini bagaimana proses siswa menemukan gerakan kreatif melalui eksplorasi permainan tradisional yang dipelajari bersama-sama. Sebelumnya siswa diarahkan untuk dapat mengenal permaianan tradisional dari sisi bentuk permainan dan nilai-nilai permainan tradisional yang dipelajarinya. Melalui kegiatan permaianan tradisional anak diarahkan mengembangkan kemampuan 
kreatif melalui kegiatan berekpresi dan berkreasi (Kamilia et al., 2019). Hasil peneletian ini mendukung penelitian sebelumnya yang mengolah permainan tradisional sebagai sumber gagasan mengolah gerak kreatif siswa.

Dalam permaian tradisional di dalamnya terdapat lagu yang dinyanyikan oleh anak yang memainkan permainan itu (Gloriani, 2013). Materi ini yang dijadikan sebagai bahan materi pelajaran untuk lebih mengakrabkan permainan tradisional kepada anak. (Sunaryo, 2016) lagu dalam permaianan tradisional dan bentuk permainan yang dijadikan sebagai sumber ajar yang diberikan kepada siswa sebagai salah satu stimulus dalam melakukan proses kreatif dalam tari. Namun dalam kegiatan sebelumnya proses pemberian materi pembelajaran tari belum dilakukan untuk membentuk karakter kreatif siswa yang dapat dilakukan melalui beberapa tahapan pembelajaran seperti berdoa, menyanyikan lagu nasional, eksplorasi, kreasi, presentasi dan evaluasi. Tahapan-tahapan pembelajaran tersebut yang dilakukan dalam kegiatan ekstrakurikuler tari yang diterapkan dalam peneltian ini.

Proses kreatif dalam pembelajaran tari melalui permaianan tradisional dalam penelitian sebelumnya dilakukan melalui tahapan pengenalan, tahapan eksplorasi, tahap pembentukan gerak dan menyusun gerak (Lestari, 2017). Namun dalam kegiatan pembelajaran tari pada penelitian tersebut, siswa tidak diarahkan untuk mengkreasi gerak-gerak yang dilakukan dalam permainan tradisional menjadi sebuah kreasi gerak kreatif. Dalam penelitian (Sunaryo, Masunah, Narawati, \& Nugraheni, 2020) digali pontensi karakteristik permainan tradisional seperti adanya unsur gerak relationship atau gerakan yang saling berhubungan dalam permainan tradisional menjadi sumber gagasan gerak kreatif dalam tari. tetapi dalam implementasi pembelajarannya lebih ditekankan pada proses mengolah tubuh dalam mengembangkan gerak-gerak kreatif dalam permainan tradisional. Penelitian ini belum mengarahkan dalam kegiatan pembelajaran tari sebagai penguatan pendidikan karakter. Hasil penelitian ini akan mendukung beberapa hasil penelitian sebelumnya dalam upaya membentuk kebiasaan karakter kreatif siswa sekolah dasar dalam pembelajaran tari di sekolah dan dalam kehidupan sehari-hari siswa di masyarakat dan keluarga.

\section{Simpulan}

Permainan tradisional anak adalah salah satu sumber materi ajar yang dapat diberikan dalam pembelajaran ekstrakurikuler tari. Dalam pembelajarannya siswa dikenalkan terlebih dahulu materi permainan tradisional agar siswa dalam memahami materi permainan tradisional sebagai salah satu sumber ajar yang menarik untuk dipelajari dalam pembelajaran tari. Kegiatan pengenalan materi permaianan tradisional ini dilakukan melalui kegiatan aprasiasi tari kaulinan dan menampilkan beberapa gambar permainan tradisional yang sering dimainkan oleh anak. Setelah mengenal materi permaianan tradisional anak diarahkan untuk dapat mengeksplorasi dan mengkreasi ulang bentuk permainan tradisional menjadi sebuah tarian kreasi. Beberapa tahapan kegiatan inti tersebut yang menjadi penekanan pembelajaran kreatif yang dilakukan siswa dalam kegiatan ekstrakurikuler tari yang diterapkan selama penelitian. Selain itu, dalam kegiatan pembelajarannya, tahapan kegiatan berdoa, menyanyikan lagu nasional, belajar secara mandiri dan kreatif serta kegiatan apresiasi adalah tahapan kegiatan pembelajaran untuk membetuk karakter siswa dalam aspek karakter religious, nasionalisme, mandiri, gotong royong dan integritas. Tahapan-tahapan pembelajaran tersebut selalu dilakukan dalam pembelajaran dengan tujuan untuk mendidik karakter baik pada anak agar menjadi pembiasaan dalam kehidupan sehari-harinya. 


\section{Referensi}

Ashley, L. (2019). Let's Get Creative about Creativity in Dance Literacy: Why, Why Not, and How? Journal of Movement Arts Literacy, 1(1).

Brown, A. K. (2014). A model for dance education: Promoting personal voice and communal learning. International Journal of Education Through Art, 10(2), 179-188. https://doi.org/10.1386/eta.10.2.179_1

Brugar, K. A., \& Roberts, K. L. (2017). Seeing Is Believing: Promoting Visual Literacy in Elementary Social Studies. Journal of Teacher Education, 68(3), 262-279. https://doi.org/10.1177/0022487117696280

Budiman, A., Nugraheni, T., \& Purnomo, P. (2020). The Effect of Architecture of Arts Education Tourism Towards Interest in Learning Arts for High School Students. $20(2), 117-125$.

Chappell, K. (2007). Creativity in primary level dance education: Moving beyond assumption. Research in Dance Education, 8(1), 27-52.

Chappell, K., \& Hathaway, C. (2019). Creativity and Dance Education Research. In Oxford Research Encyclopedia of Education.

Connell, J. (2009). Dance education: an examination of practitioners' perceptions in secondary schools and the necessity for teachers skilled in the pedagogy and content of dance. Research in Dance Education, 10(2), 115-130. https://doi.org/10.1080/14647890903019440

Connery, M. C., John-Steiner, V., \& Marjanovic-Shane, A. (2010). Vygotsky and creativity: A cultural-historical approach to play, meaning making, and the arts (Vol. 5). Peter Lang.

Davenport, D. (2006). Building a dance composition course: an act of creativity. Journal of Dance Education, 6(1), 25-32.

Davis, J. (1995). Laban Movement Analysis: A key to individualizing children's dance. Journal of Physical Education, Recreation \& Dance, 66(2), 31-33.

Dermawan, W., Purnama, C., \& Mahyudin, E. (2020). Penguatan "Kaulinan Barudak Sunda " sebagai permainan tradisional di Kecamatan Jatinangor Strengthening "Kaulinan Barudak Sunda " as a traditional game in Jatinangor District. 7(1), 1-15.

Dimondstein, G. (1974). Exploring the arts with children. Macmillan New York.

Georgios, L. (2017). The Transformation of Traditional Dance from Its First to Its Second Existence: The Effectiveness of Music - Movement Education and Creative Dance in the Preservation of Our Cultural Heritage. Journal of $\begin{array}{llll}\text { Education } \quad \text { and Training } & \text { Studies, } & 6(1), & 104 .\end{array}$ https://doi.org/10.11114/jets.v6i1.2879

Georgios, L. (2018). The Transformation of Traditional Dance from Its First to Its Second Existence: The Effectiveness of Music-Movement Education and Creative Dance in The Preservation of Our Cultural Heritage. Journal of Education and Training Studies, 6(1), 104-112.

Gloriani, Y. (2013). Kajian Nilai-Nilai Sosial Dan Budaya Pada Kakawihan Kaulinan Barudak Lembur Serta Implementasinya Dalam Pembelajaran Bahasa Dan Sastra Indonesia Berbasis Multikultural. Lokabasa, 4(2). https://doi.org/10.17509/jlb.v4i2.3147

H'Doubler, M. N., \& Claxton, W. L. (1957). Dance: a Creative Art Experience by Margaret N. H'Doubler. University of Wisconsin Press.

Kamilia, Herdhiana, R., \& Hermawan, L. (2019). Pengaruh Implementasi Model Pembelajaran SAVI Terhadap Kreativitas Peserta Didik Dalam Tari Kaulinan Barudak di Sekolah Dasar. 17(1), 1-6.

Kanwisher, N., McDermott, J., \& Chun, M. M. (1997). The fusiform face area: a module in human extrastriate cortex specialized for face perception. Journal of Neuroscience, 17(11), 4302-4311.

Karmini, N. N. (2020). Pendidikan Karakter Dalam Cerita Rakyat Rajapala. Mudra Jurnal Seni Budaya, 35(1), 22-29. https://doi.org/10.31091/mudra.v35i1.994

Kassing, G., \& Jay, D. M. (2020). Dance teaching methods and curriculum design: 
comprehensive K-12 dance education. Human Kinetics Publishers.

Koff, S. R. (2000). Toward a definition of dance education. Childhood Education, $77(1), 27-32$.

Lavender, L. (2006). Creative Process Mentoring: Teaching the "Making" in DanceMaking. Journal of Dance Education, 6(1), 6-13. https://doi.org/10.1080/15290824.2006.10387306

Lestari, A. T. (2017). Pembelajaran Tari Kreatif Melalui Kaulinan Budak Lembur Di Sekolah Dasar. NATURALISTIC: Jurnal Kajian Penelitian Pendidikan Dan Pembelajaran, 1(2), 102-111. https://doi.org/10.35568/naturalistic.v1i2.3

Lindqvist, G. (2001). The relationship between play and dance. Research in Dance Education, 2(1), 41-52.

Luthviyani, I. R., Setianingsih, E. S., \& Handayani, D. E. (2019). Analisis Pelaksanaan Ekstrakurikuler Pramuka Terhadap Nilai-nilai Karakter Siswa di SD Negeri Pamongan 2. Jurnal PGSD: Jurnal Ilmiah Pendidikan Guru Sekolah Dasar, 12(2), 113-122.

Maletic, V. (2011). Body-space-expression: The development of Rudolf Laban's movement and dance concepts (Vol. 75). Walter de Gruyter.

Marques, A. I. P. (2016). As Conceções pessoais da Criatividade em Dança dos professores e alunos do Ensino Artístico.

McElmeel, S. L. (2002). Character education: a book guide for teachers, librarians, and parents.

Murphy, Madonna M., S. L. B. (2009). Character Education: Overcoming Prejudice. New York: Chelsea House.

Press, C. M., \& Warburton, E. C. (2007). Creativity research in dance. In International handbook of research in arts education (pp. 1273-1290). Springer.

Redfern, H. B. (1982). Concepts in modern educational dance.

Risner, D. (2010). Dance education matters: Rebuilding postsecondary dance education for twenty-first century relevance and resonance. Arts Education Policy Review, 111(4), 123-135.

Rosala, D., \& Budiman, A. (2020). Local Wisdom-based Dance Learning: Teaching Characters to Children through Movements. 7(3), 304-326. https://doi.org/10.17509/mimbar-sd.v7i3.28185

Schwartz, P. (1993). Creativity and dance: Implications for pedagogy and policy. Arts Education Policy Review, 95(1), 8-16.

Setiono, P., Yuliantini, N., \& Dadi, S. (2020). Meningkatkan Nilai Karakter Peserta Didik Melalui Penerapan Model Pembelajaran Project Based Learning. Jurnal PGSD: Jurnal Ilmiah Pendidikan Guru Sekolah Dasar, 13(1), 86-92.

Smith-Autard, J M. (2010). Dance composition: a practical guide to creative success in dance making.

Smith-Autard, Jacqueline M. (2002). The art of dance in education. A\&C Black.

Smith-Autard, Jacqueline Mary. (2000). Dance composition. Psychology Press.

Sööt, A., \& Viskus, E. (2013). Teaching dance in the 21st century: A literature review. The European Journal of Social \& Behavioural Sciences, 7(4), 1193.

Sööt, A., \& Viskus, E. (2014). Contemporary Approaches to Dance Pedagogy - The Challenges of the 21st Century. Procedia - Social and Behavioral Sciences, 112(Iceepsy 2013), 290-299. https://doi.org/10.1016/j.sbspro.2014.01.1167

Stinson, S. (1988). Creative dance for preschool children. Journal of Physical Education, Recreation \& Dance, 59(7), 52-56.

Stinson, S. W. (2010). Questioning our past and building a future: Teacher education in dance for the 21st century. Journal of Dance Education, 10(4), 136-144.

Studente, S., Seppala, N., \& Sadowska, N. (2016). Facilitating creative thinking in the classroom: Investigating the effects of plants and the colour green on visual and verbal creativity. Thinking Skills and Creativity, 19, 1-8. https://doi.org/10.1016/j.tsc.2015.09.001

Sunaryo, A. (2016). Kaulinan Barudak Sebagai Sumber Ajar Dalam Penciptaan Tari Anak Di Sekolah Dasar. 2(1), 51-57. 
Sunaryo, A., Masunah, J., Narawati, T., \& Nugraheni, T. (2020). Gerak Relationship Pada Permainan Anak Sunda Sebagai Sumber Penciptaan Komposisi Tari Anak. Jurnal Obsesi: Jurnal Pendidikan Anak Usia Dini, 4(2), 1076-1086.

Torrents Martín, C., Ric, Á., \& Hristovski, R. (2015). Creativity and emergence of specific dance movements using instructional constraints. Psychology of Aesthetics, Creativity, and the Arts, 9(1), 65.

Von Laban, R. (1975). Modern educational dance. Princeton Book Company Pub.

Warburton, E. C. (2005). Choreographic outcomes: Improving dance composition. JSTOR. 